SUPPORTING INFORMATION FOR:

\title{
Performance Enhancement of Polymer Electrode Materials for Lithium-Ion Batteries: From a Rigid Homopolymer to Soft Copolymers
}

Jixing Yang, ${ }^{*}{ }^{\dagger}$ Yeqing Shi, ${ }^{\dagger}$ Mengjie Li,${ }^{\dagger}$ Pengfei Sun,${ }^{\dagger}$ and Yunhua $\mathrm{Xu}^{*}, \dagger,+$

$\dagger$ School of Materials Science and Engineering, Key Laboratory of Advanced Ceramics and Machining Technology (Ministry of Education), and Tianjin Key Laboratory of Composite and Functional Materials, Tianjin University, Tianjin 300072, China.

$\$$ Collaborative Innovation Center of Chemical Science and Engineering (Tianjin), Tianjin 300072, China.

Corresponding Authors

Jixing Yang, E-mail: jackieyang@ @ tju.edu.cn

Yunhua Xu, E-mail: yunhua.xu@tju.edu.cn 


\section{EXPERIMENTAL SECTION}

1.1. Materials. All process involving air- and/or moisture-sensitive compounds was carried out in MBraun glovebox or under an argon atmosphere using standard Schleck technique unless otherwise noted. Anhydrous solvents used in this work were purified by solvent purification system purchased from MBraun. All materials were purchased from Sigma-Aldrich or Alfa-Aesar and used without further purification if not mentioned otherwise. Grubbs third generation Catalyst (G3) was synthesized according to the method reported previously and stored in the glovebox. ${ }^{1}$ The synthesis of Monomer $\mathbf{1}$ and its homopolymers could be found in our recently published paper. $^{2}$

1.2. Characterization. The ${ }^{1} \mathrm{H}$ and ${ }^{13} \mathrm{C}$ NMR spectra were recorded on a Bruker-400 MHz spectrometer $\left(399.65 \mathrm{MHz}\right.$ for ${ }^{1} \mathrm{H}$ and $100.40 \mathrm{MHz}$ for ${ }^{13} \mathrm{C}$, respectively) at $25{ }^{\circ} \mathrm{C}$. The molecular weights and the molecular weight distributions of the polymer samples were determined at $35{ }^{\circ} \mathrm{C}$ by a waters 1525 type gel permeation chromatography (GPC). Tetrahydrofuran (THF) or N,N-dimethyl formamide (DMF) was employed as the solvent at a flow rate of $1.0 \mathrm{~mL} / \mathrm{min}$, and the calibration was made by polystyrene standard Easi-Cal PS-1 (PL Ltd). Differential scanning calorimetry (DSC) measurements were performed on a DSC1 Stare System (Mettler Toledo Instruments, Swiss) under nitrogen atmosphere, which had been calibrated for temperature and melting enthalpy by using indium as a standard. The samples were heated at a rate of $10{ }^{\circ} \mathrm{C} / \mathrm{min}$ and cooled down at a rate of $10{ }^{\circ} \mathrm{C} / \mathrm{min}$. Glass transition temperatures $\left(T_{\mathrm{g}} \mathrm{s}\right)$ were taken from the second heating run and were read as the midpoint of change in heat capacity. Thermo gravimetric analyses (TGA) were performed with a Perkin-Elmer Pyris 1 with a heating rate of $10{ }^{\circ} \mathrm{C} / \mathrm{min}$ from $40{ }^{\circ} \mathrm{C}$ to $900{ }^{\circ} \mathrm{C}$ in nitrogen. Scanning electron microscopy (SEM) tests were 
conducted on an S-4800 SEM (Hitachi, Japan) operated at $5 \mathrm{KV}$.

\subsection{Synthesis of Comonomer 2 [5-norbornene-2-yl methyl propionate]. An} oven dried $250 \mathrm{~mL}$ round-bottom flask equipped with a magnetic stirrer, a dropping funnel was added with $15.0 \mathrm{~g}(0.121 \mathrm{~mol})$ 5-norbornene-2-methanol, $18.4 \mathrm{~g}(0.182$ mol) dried triethylamine (TEA) and $150 \mathrm{~mL}$ dried dichloromethane (DCM) under nitrogen. The flask was cooled to $0{ }^{\circ} \mathrm{C}$ through ice bath before the Propanyl chloride (16.7 $\mathrm{g}, 0.182 \mathrm{~mol})$ was added dropwise for 15 minutes under vigorous stirring. The mixture was stirred for $12 \mathrm{~h}$ under room temperature after the addition was completed. The mixture then was extracted with $1 \mathrm{~N} \mathrm{HCl}(150 \mathrm{~mL} \times 3)$, sat. $\mathrm{NaHCO}_{3}(150 \mathrm{~mL} \times$ 3), water $(150 \mathrm{~mL} \times 2)$, and brine $(150 \mathrm{~mL} \times 2)$, dried over $\mathrm{MgSO}_{4}$, filtered and evaporated. The residue was purified by column chromatography (20:1, petroleum ether: ethyl acetate), and the clean fractions combined and evaporated to afford the desired compound as a clear liquid (19.6 g, 90\% yield). The monomer was dried by $\mathrm{CaH}_{2}$ and distilled under reduced pressure before polymerization. ${ }^{1} \mathrm{H}$ NMR $\left(\mathrm{CDCl}_{3}\right.$, $298 \mathrm{~K})($ endo: exo $=1: 0.44) \delta: 6.15(\mathrm{q}, 1 \mathrm{H}), 6.09(\mathrm{~m}, 0.88 \mathrm{H}), 5.93(\mathrm{q}, 1 \mathrm{H}), 4.16(\mathrm{q}$, $0.44 \mathrm{H}), 3.97(\mathrm{q}, 0.44 \mathrm{H}), 3.86(\mathrm{q}, 1 \mathrm{H}), 3.66(1,1 \mathrm{H}), 2.87(\mathrm{~s}, 1 \mathrm{H}), 2.83(\mathrm{~s}, 0.44 \mathrm{H}), 2.81$ (s, 1H), $2.70(\mathrm{~s}, 0.44 \mathrm{H}), 2.43-2.30(\mathrm{~m}, 4 \mathrm{H}), 1.87-1.81(\mathrm{~m}, 1 \mathrm{H}), 1.76-1.68(\mathrm{~m}, 0.44 \mathrm{H})$, $1.47-1.43(\mathrm{~m}, 1 \mathrm{H}), 1.37-1.29(\mathrm{~m}, 1.32 \mathrm{H}), 1.28-1.24(\mathrm{~m}, 1.44 \mathrm{H}), 1.15(\mathrm{~m}, 4.88 \mathrm{H}), 0.56$

(m, 1H) ppm; ${ }^{13} \mathrm{C}$ NMR $\left(\mathrm{CDCl}_{3}, 298 \mathrm{~K}\right) \delta: 174.35,174.25,137.43,136.80,136.14$, $132.10,68.30,67.61,49.29,44.87,43.80,43.59,42.14,41.52,37.94,37.78,29.50$, $28.92,27.53,9.12,9.09 \mathrm{ppm}$.

\subsection{Typical polymerization procedure of copolymers (CoP100-x).} Polymerizations were carried out in a dried $100 \mathrm{~mL}$ round bottom Schleck flask equipped with a magnetic stirrer at room temperature (RT) under $\mathrm{N}_{2}$ with degassed DCM as a solvent. The accurately weighed monomers (total weight among 0.5-0.8 g) 
were added into the flask and DCM (40-60 mL) was added through a syringe. When the monomers were completely dissolved, the catalyst $\mathbf{G 3}$, which was weighted in the glove-box and dissolved in $0.5 \mathrm{~mL}$ DCM, was added into the monomers solution. After stirring at RT for 2 hours, the polymerization was terminated by adding a few drops of ethyl vinyl ether (EVE) and stirred for 30 minutes to ensure complete termination. A few drops of solution were extracted into the NMR tube and dried under vacuum for NMR tests. The resultant polymer solution was precipitated in methanol and collected, then was washed twice by the methanol and dried under reduced pressure for 24 hours at $40{ }^{\circ} \mathrm{C}$. The yields are high than $90 \%$.

1.5. Electrode preparation. The composite electrodes of polymers were prepared by mixing polymer with multiwalled carbon nanotubes (MWCNTs) and poly(vinylidenefluoride) (PVDF, as binder) in a ratio of 40:40:20 by weight. The weighted polymer was first dissolved completely in DCM. Then MWCNTs was then added into the polymer solution. Thereafter the mixture was stirred and ultrasonically dispersed until DCM was completely volatilized in a well-functioning fume hood. The dried mixture was further mixed by hand milling also for about 1 hour. The binder and a small amount of N-Methyl pyrrolidone (NMP) were then added to form a slurry. After the slurry was ground by hand milling for another 1 hour, the slurry was cast onto aluminum current collector using a doctor blade. After NMP was volatilized at $50{ }^{\circ} \mathrm{C}$ for 4 hours, the electrode was then cut into circular disks $(9 \mathrm{~mm}$ diameter $)$ and dried at $90{ }^{\circ} \mathrm{C}$ under vacuum for 12 hours before battery assembly. The mass loading of the polymer electrodes is $0.5-1.0 \mathrm{mg} / \mathrm{cm}^{2}$.

1.6. Batteries assembling and electrochemical measurements. The coin-type cells were fabricated in the Ar-filled gloveboxes (Mikrouna Co., $\mathrm{H}_{2} \mathrm{O}$ and $\mathrm{O}_{2}<0.1$ ppm). Lithium foil was used as the anode, and $2 \mathrm{M}$ lithium 
bis(trifluoromethanesulfonyl)imide (LiTFSI) in mixture solvent of 1,3-dioxolane (DOL) and 1,2-dimethoxyethane (DME) $(\mathrm{v} / \mathrm{v}=1 / 1,40 \mu \mathrm{L})$ as electrolyte, and porous polypropylene sheet (Celgard 2400) as the separator.

Cyclic voltammogram $(\mathrm{CV})$ at a scan rate of $0.1 \mathrm{mV} / \mathrm{s}$ between 1.5 and $3.0 \mathrm{~V}(v s$. $\mathrm{Li}^{+} / \mathrm{Li}$ ) and electrochemical impedance spectroscopy (EIS) in the frequency of 1000000-0.1 $\mathrm{Hz}$ at $5 \mathrm{mV}$ amplitude were recorded using Solartron 1470 Electrochemical Interface. The galvanostatic charge-discharge tests were performed on LAND 2001A between 1.5 and $3.0 \mathrm{~V}\left(v s . \mathrm{Li}^{+} / \mathrm{Li}\right)$.

\section{Supported Results and Discussion (Tables and Figures)}

\subsection{Polymerization conditions and summarized results}

Table S1. Conditions and homo/copolymerization results ${ }^{a}$

\begin{tabular}{cccccccccc}
\hline Entry & $\begin{array}{c}\mathrm{m}^{b} \\
(\mathrm{mg})\end{array}$ & $\begin{array}{c}\mathrm{m}^{c}{ }^{c} \\
(\mathrm{mg})\end{array}$ & $\begin{array}{c}\mathrm{mg}^{d}{ }^{d} \\
(\mathrm{mg})\end{array}$ & $\begin{array}{c}\mathrm{V}_{\mathrm{DCM}} \\
(\mathrm{mL})\end{array}$ & $\begin{array}{c}\text { Yield } \\
(\mathrm{g}, \%)\end{array}$ & $M_{\mathrm{n}}{ }^{e}$ & $\mathrm{PDI}^{e}$ & $\begin{array}{c}T_{\mathrm{g}}{ }^{f} \\
\left({ }^{\circ} \mathrm{C}\right)\end{array}$ & $\begin{array}{c}T_{\mathrm{d}}{ }^{g} \\
\left({ }^{\circ} \mathrm{C}\right)\end{array}$ \\
\hline 1 & 550.0 & $-{ }^{h}$ & 7.8 & 50 & $0.52,96$ & 36200 & 1.23 & 152 & 340 \\
\hline 2 & 735.3 & 38.7 & 12.4 & 60 & $0.71,91$ & 20800 & 1.21 & 134 & 353 \\
\hline 3 & 492.3 & 54.7 & 9.7 & 40 & $0.52,92$ & 19400 & 1.16 & 123 & 349
\end{tabular}

${ }^{a}$ Conditions: $[$ monomer(s)]/[G3] $=100$, room temperature, polymerization for 2 hours.

${ }^{b}$ The weight of feeding Monomer 1. ${ }^{c}$ The weight of feeding Comonomer 2. ${ }^{d}$ The weight of feeding G3. ${ }^{e}$ Obtained by GPC analysis with chloroform as the elute solvent. ${ }^{f}$ Obtained by DSC. ${ }^{g}$ Obtained by TGA. ${ }^{h}$ Homopolymerization with no comonomer.

\subsection{Synthesis of homopolymer P100}




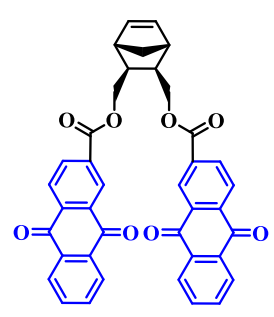

Monomer 1

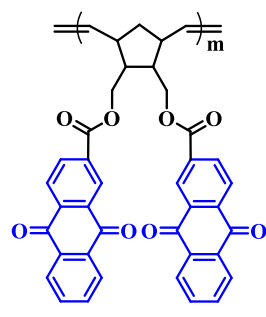

Polymer $(\mathbf{P} \boldsymbol{x})$

Figure S1. Syntheses of linear homopolymers, G3 = Grubbs third generation catalyst.

2.3 Synthesis of Comonomer 2
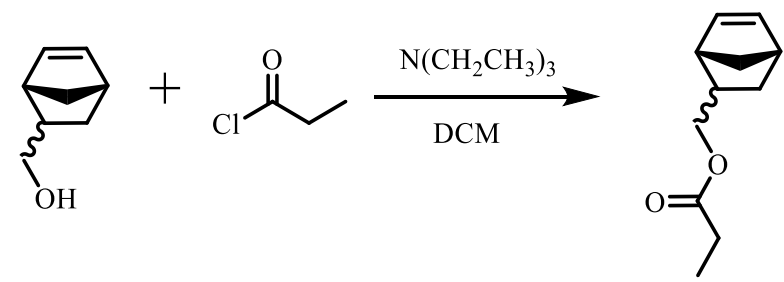

Figure S2. Synthesis of Comonomer 2.

\section{$2.4{ }^{1} \mathrm{H}$ NMR spectra of copolymers and the calculation}
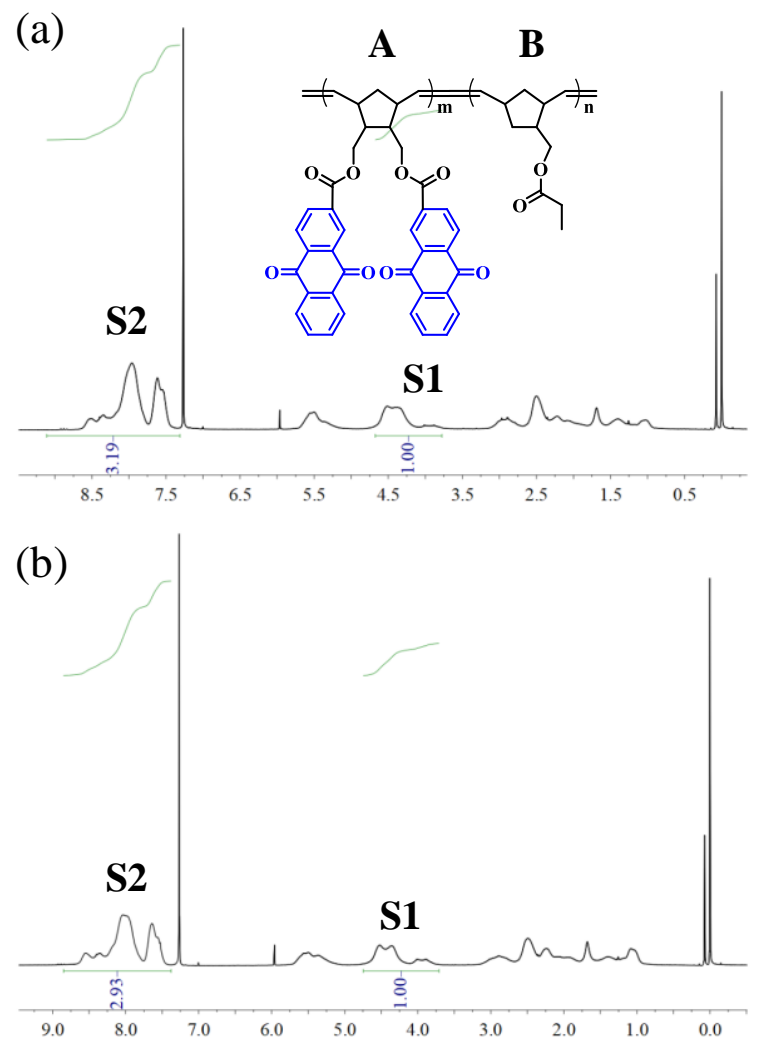

Figure S3. ${ }^{1} \mathrm{H}$ NMR spectra of copolymers with Comonomer 2 weight ratios of $5 \%$ (a: CoP100-5) and 10\% (b: CoP100-10). No monomer peak was detected. 
The components of A and B are calculated from the following formula:

$$
\begin{gathered}
4 A+2 B=S_{1} \\
14 A=S_{2}
\end{gathered}
$$

The results are summarized as below, where $\mathrm{B} / \mathrm{A}$ is the molar ratio of $\mathrm{B}$ (Comonomer 2) to A (main monomer 1).

Table S2. Theoretical and calculated values of [Comonomer 2]/[Monomer 1] (i.e. B/A as show in Figure S3)

\begin{tabular}{|c|c|c|}
\hline B/A & theoretical value & $\begin{array}{l}\text { Calculated from }{ }^{1} \mathrm{H} \\
\text { NMR }\end{array}$ \\
\hline CoP100-5 & 0.182 & 0.191 \\
\hline CoP100-10 & 0.384 & 0.389 \\
\hline
\end{tabular}

\subsection{Results of electrochemical impedance spectroscopy tests}

Table S3 Results of electrochemical impedance spectroscopy tests

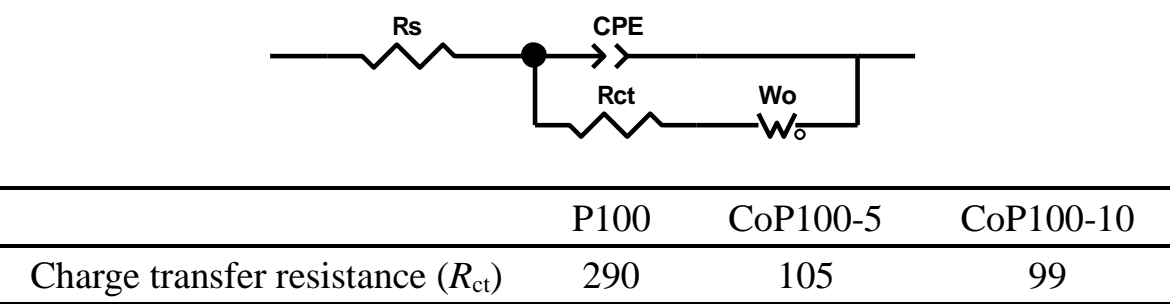

\subsection{Selected discharge/charge profiles of CoP100-10}




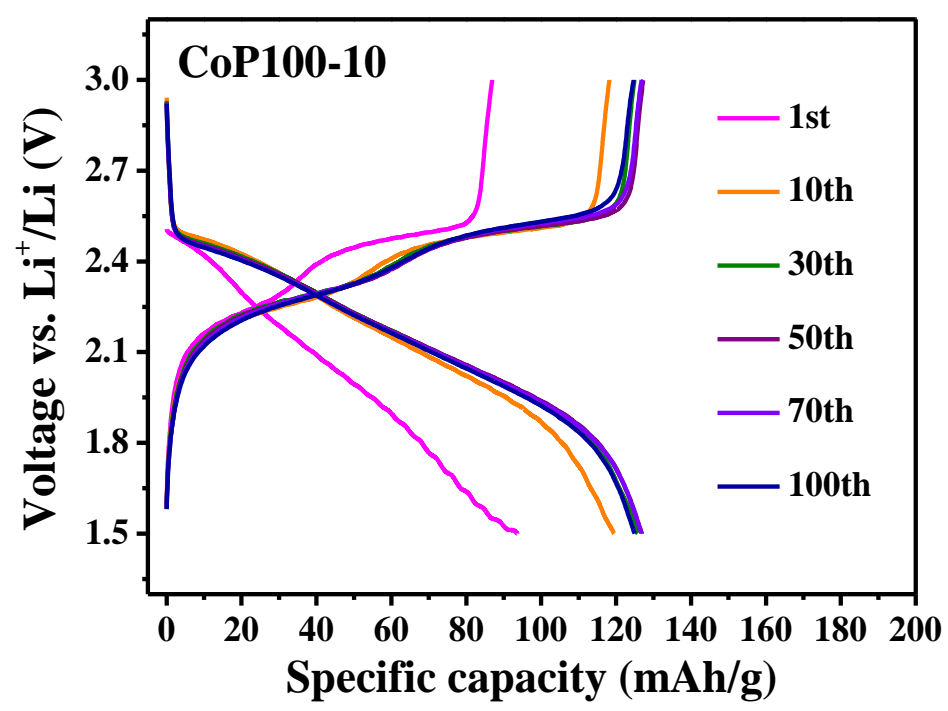

Figure S4. Selected galvanostatic discharge/charge curves of copolymer CoP100-10 at 0.1C.

\section{REFERENCES}

(1) Love, J. A.; Morgan, J. P.; Trnka, T. M.; Grubbs, R. H. A Practical and Highly Active Ruthenium-Based Catalyst that Effects the Cross Metathesis of Acrylonitrile. Angew. Chem. Int. Ed. 2002, 41, 4035-4037.

(2) Yang, J.; Shi, Y.; Sun, P.; Xiong, P.; Xu, Y. Optimization of Molecular Structure and Electrode Architecture of Anthraquinone Containing Polymer Cathode for High Performance Lithium-Ion Batteries. ACS Appl. Mater. Interfaces 2019, 11, $42305-42312$. 